Neurosurg Focus 6 (3):Article 1, 1999

\title{
Intraoperative validation of functional magnetic resonance imaging and cortical reorganization patterns in patients with brain tumors involving the primary motor cortex
}

Javier Fandino, M.D., Spyros S. Kollias, M.D., Heinz Gregor Wieser, M.D., Anton Valavanis, M.D., and Yasuhiro Yonekawa, M.D.

Departments of Neurosurgery and Neurology, and Institute of Neuroradiology, University Hospital of Zurich, Zurich, Switzerland

The purpose of the present study was to compare the results of functional magnetic resonance (fMR) imaging with those of intraoperative cortical stimulation in patients who harbored tumors close to or involving the primary motor area and to assess the usefulness of fMR imaging in the objective evaluation of motor function as part of the surgical strategy in the treatment of these patients.

A total of 11 consecutive patients, whose tumors were near to or involving the central region, underwent presurgical blood oxygen level-dependent fMR imaging while performing a motor paradigm that required the patients to clench and spread their hands contra- and ipsilateral to the tumor. Statistical cross-correlation functional maps covering the primary and secondary motor cortical areas were generated and overlaid onto high-resolution anatomical MR images. Intraoperative electrical cortical stimulation was performed to validate the presurgical fMR imaging findings. In nine (82\%) of 11 patients, the anatomical fMR imaging localization of motor areas could be verified by intraoperative electrical cortical stimulation. In seven patients two or more activation sites were demonstrated on fMR imaging, which were considered a consequence of reorganization phenomena of the motor cortex: contralateral primary motor area (nine sites), contralateral premotor area (four sites), ipsilateral primary motor area (two sites), and ipsilateral premotor area (four sites).

Functional MR imaging can be used to perform objective evaluation of motor function and surgical planning in patients who harbor lesions near or involving the primary motor cortex. Correlation between fMR imaging findings and the results of direct electrical brain stimulation is high, although not $100 \%$. Based on their study, the authors believe that cortical reorganization patterns of motor areas might explain the differences in motor function and the diversity of postoperative motor function among patients with central tumors.

Key Words * motor cortex * plasticity * brain neoplasm * functional magnetic resonance imaging * electrical cortical stimulation

In patients with brain tumors involving the central area, preservation of function after surgery remains a challenge for neurosurgeons. Detailed visualization of the brain structures in magnetic resonance (MR) imaging[29] has encouraged further applications of electrophysiological techniques to correlate anatomical and functional findings in the human cortex.[3,6] More recently, advances in MR imaging technology have allowed the localization of the visual[2,11,23] and sensorimotor cortices[12,17,21,37,38] in volunteers and in patients with brain tumors. Since 1995, several groups have reported obtaining correlations between functional (f)MR imaging and intraoperative 
electrical cortical stimulation (ECS).[17,29,36,41,49-51] Efforts in these mostly preliminary studies have focused primarily on neurophysiological and/or neuroradiological aspects and, because of the novelty of the technique, have included poorly standardized protocols and selective, not consecutive, series of patients.

In the present work we attempt, by using a standardized protocol, to validate intraoperatively the fMR imaging technique for localization of the motor cortex in a consecutive series of patients with tumors in the central region. We focus primarily on the surgical applicability of this new technology and cortical reorganization phenomena observed in patients whose lesions involved the primary sensorimotor cortex.

\section{CLINICAL MATERIAL AND METHODS}

\section{Patient Population}

The study group included 11 patients (eight men and three women) with verified tumors near to or involving the central region who underwent operation over a 1-year period. The age of the patients ranged between 7 and 69 years (mean $40.6 \pm 17$ years). The histopathological diagnoses included low-grade glioma (three patients), astrocytoma World Health Organization (WHO) Grade III (one patient), oligodendroglioma (two patients), glioblastoma multiforme (two patients), metastatic tumors (two patients), and meningioma (one patient). Patient characteristics, clinical presentation, extent of resection, ECS findings, and histopathological diagnoses are summarized in Table 1. Two patients in this study presented with recurrent tumors (Cases 6 and 9; Table 1). A total of five patients presented with preoperative focal neurological deficits (motor deficit or aphasia), and six had a history of seizures (two of whom were considered to suffer intractable epilepsy). Perioperatively, all patients received dexamethasone and antiepileptic medications.

TABLE 1

SUMMRY OF CL NICAL, RADILOGKAL, INTRA- AND POSTOPERATIYE FIND NGS IN 11 PATIENTS UNDERGONG FMR IMAGNG AND ECS

\begin{tabular}{|c|c|c|c|c|c|c|c|}
\hline $\begin{array}{l}\text { Case } \\
\text { No. }\end{array}$ & $\underset{\text { Sex }}{\text { Age }(y r s]}$ & $\begin{array}{l}\text { Diagnosis } \\
\text { ILocation }\end{array}$ & $\begin{array}{l}\text { Preop } \\
\text { Findings }\end{array}$ & $\begin{array}{l}\text { flviR } \\
\text { Imaging }\end{array}$ & $\mathrm{ECS}$ & $\begin{array}{l}\text { Extent of } \\
\text { Resectiont }\end{array}$ & $\begin{array}{l}\text { Postop } \\
\text { Findings }\end{array}$ \\
\hline 1 & $48, F$ & $\begin{array}{l}\text { astrocytoma } \\
\text { (WWO III)At } \\
\text { postoentral }\end{array}$ & $\begin{array}{l}\text { SPS; mild } \\
\text { rt arm } \\
\text { paresis }\end{array}$ & $\begin{array}{l}\text { contralat Ml } \\
\& \text { SMA; } \\
\text { ipsilat Mill }\end{array}$ & $\begin{array}{l}\text { good correlation/ } \\
\text { rt hand tonic re- } \\
\text { sponse }\end{array}$ & total & $\begin{array}{l}\text { im proved } \\
\text { motor deficit }\end{array}$ \\
\hline 2 & $32, M$ & $\begin{array}{l}\text { fitrillary astro- } \\
\text { cytoma (wiHo } \\
\text { II)/lt preoen- } \\
\text { tral gurus }\end{array}$ & $\begin{array}{l}\text { depression; } \\
\text { no focal } \\
\text { deficit }\end{array}$ & $\begin{array}{l}\text { contralat MI, } \\
\text { SM д \& MII }\end{array}$ & $\begin{array}{l}\text { good correlation/ } \\
\text { rt facial-trachial } \\
\text { response }\end{array}$ & total & $\begin{array}{l}\text { tem porary } \\
\text { dysphasia }\end{array}$ \\
\hline 3 & $27, M$ & $\begin{array}{l}\text { meningothelial } \\
\text { meningioma } \\
\text { (Wü } \mathrm{HOl} \text { dt } \\
\text { costoentral }\end{array}$ & $\begin{array}{l}\text { headache; } \\
\text { mild it arm } \\
\text { paresis }\end{array}$ & $\begin{array}{l}\text { contralat MI } \\
\& \text { SMA }\end{array}$ & $\begin{array}{l}\text { good correlation/ } \\
\text { rt clonic hand } \\
\text { response }\end{array}$ & total & $\begin{array}{l}\text { no additional } \\
\text { deficit }\end{array}$ \\
\hline 4 & $50, M$ & $\begin{array}{l}\text { metastasis (lung } \\
\text { carcinom a)/ } \\
\text { rt parie tal }\end{array}$ & $\begin{array}{l}\text { It hemi pare- } \\
\text { sis }\end{array}$ & $\begin{array}{l}\text { contralat MI, } \\
\text { ipsilat MII }\end{array}$ & $\begin{array}{l}\text { good correlation/ } \\
\text { It hand response }\end{array}$ & total & $\begin{array}{l}\text { initial de- } \\
\text { terioration }\end{array}$ \\
\hline 5 & $57, M$ & $\begin{array}{l}\text { metastasis } \\
\text { (melanoma)/ } \\
\text { rt parietal }\end{array}$ & $S P S$ & $\begin{array}{l}\text { contralat Mll } \\
\& \text { Ml }\end{array}$ & $\begin{array}{l}\text { good correlation/ } \\
\text { It hand response }\end{array}$ & total & $\begin{array}{l}\text { tem porary } \\
\text { paresis }\end{array}$ \\
\hline 6 & $32, F$ & $\begin{array}{l}\text { oligoastrocytoma } \\
\text { (WW } \mathrm{HO} \text { II)/rt } \\
\text { perietal }\end{array}$ & $\mathrm{SPS}$ & $\begin{array}{l}\text { ipsilat MI \& } \\
\text { MIII; contralat } \\
\text { MIII }\end{array}$ & $\begin{array}{l}\text { good correlation/ } \\
\text { It hand response }\end{array}$ & subtotal & no deficit \\
\hline 7 & $65, M$ & $\begin{array}{l}\text { glioblastoma } \\
\text { multiforme irt } \\
\text { frontoparie tal }\end{array}$ & SMPS & contralat Ml & no correlation & total & $\begin{array}{l}\text { temporary It } \\
\text { arm paresis }\end{array}$ \\
\hline 8 & $7, M$ & $\begin{array}{l}\text { fitrillary astro- } \\
\text { cytoma (w'HO } \\
\text { II)it parietal }\end{array}$ & SP S; GTCS & $\begin{array}{l}\text { ipsilat MI; } \\
\text { contralat MII }\end{array}$ & no correlation & total & no deficit \\
\hline 9 & $38, M$ & $\begin{array}{l}\text { oligodendrogli- } \\
\text { oma (W/HO III)/ } \\
\text { rt frontal }\end{array}$ & $\begin{array}{c}\text { SP S, GTCS; } \\
\text { headache }\end{array}$ & $\begin{array}{l}\text { contralat MII, } \\
\& \text { MII }\end{array}$ & $\begin{array}{l}\text { good correlation/ } \\
\text { It hand and foot } \\
\text { response }\end{array}$ & partial & no deficit \\
\hline 10 & $50, M$ & $\begin{array}{l}\text { astrocytoma } \\
\text { (WW } \mathrm{HO} \text { II)/It } \\
\text { frontoperie tal }\end{array}$ & aphasia & contralat Ml & $\begin{array}{l}\text { good correlation/ } \\
\text { rt hand response }\end{array}$ & partial & no deficit \\
\hline 11 & 69. F & aliotlastoma mul- & headache & contralat Ml & aood correlation/ & cartial & no deficit \\
\hline
\end{tabular}




\section{Magnetic Resonance Imaging Studies}

Preoperatively, all patients underwent morphological and fMR imaging examinations performed during the same imaging session by using a 1.5 tesla whole-body MR imaging system equipped with an ultrafast, three-axes gradient system (maximum amplitude 22 milli-Tesla/meter, rise time $184 \mathrm{msec}$, and slew rate 120 milli-Tesla/meter/msec).

A standard product whole-head transmit-receive coil and foam cushions and straps were used to immobilize the patient's head comfortably. After anatomical localizer images had been obtained in the sagittal plane, conventional $\mathrm{T}_{1}$-weighted spin-echo sequences (repetition time [TR] $600 \mathrm{msec}$; echo time [TE] $20 \mathrm{msec}$ ) and proton density- and $\mathrm{T}_{2}$-weighted (TR $3500 \mathrm{msec}$; TE 17/120 msec) fast spin-echo sequences were acquired over the whole brain according to a routine presurgical imaging protocol. The fMR imaging procedure was started by identifying the course of the central sulcus on the sagittal localizer images by using previously described anatomical landmarks.[30] Spin-echo $\mathrm{T}_{1}$-weighted (TR $600 \mathrm{msec}$; TE $20 \mathrm{msec}$ ) anatomical slices with an inplane resolution of $0.8 \mathrm{X} 1.2 \mathrm{~mm}$ and a section thickness of $5 \mathrm{~mm}$ were collected to demonstrate the structural anatomy of the selected region. Careful placement of six to seven contiguous slices, parallel to the anteroposterior commissure line, allowed adequate coverage of the pre- and postcentral sensorimotor cortex, premotor frontal, and superior parietal cortical areas. Regional changes in neuronal activity in the motor cortex were detected using the blood oxygen level-dependent MR technique.[31] Images of the brain produced by this technique reflect local responses in cerebral blood oxygenation during neuronal activity. A subtle decrease in the deoxygenation of oxyhemoglobin results in local magnetic-susceptibility changes that decrease the apparent transverse relaxation time (T2*) and, hence, increase the signal intensity of the activated regions. Gradient-echo $\mathrm{T}_{2}{ }^{*}$-weighted (TR $3000 \mathrm{msec}$, TE 40 msec, flip angle of 40š), single-shot, echo planar images of the same slice thickness and orientation as the $\mathrm{T}_{1}$-weighted anatomical images and in-plane resolution of $3.1 \times 3.1 \mathrm{~mm}$ were obtained. Forty images were acquired in an interleaved manner in each slice during five alternating periods of rest-task performance (five, 10 , 10,10 , and five images in each period, respectively) for a total of 240 (six slice experiments performed in five patients) or 300 (seven slice experiments performed in the remaining patients) images. In all patients the motor task consisted of self-paced clenching and spreading of the hand on the side contralateral and ipsilateral to the tumor for the identification of the hand representation cortical areas. In four patients in whom the tumor extended into the paracentral region, the foot representation area was additionally identified by performing self-paced sequential movements of the foot and toes on the side contralateral to the lesion. Prior to initiating the MR imaging session, the motor tasks were explained to and practiced by the patients, and informed consent was obtained from all of them. Verbal commands for "start" and "stop" of the task were spoken over an intercom. An observer inside the MR imaging suite controlled compliance and correct performance of the experimental paradigm. The imaging time for each functional experiment was 2 minutes, resulting in a prolongation of the routine presurgical planning protocol by approximately 10 to 15 minutes (including the anatomical series for the subsequent overlays and the reconstruction time for the functional series). After administration of intravenous gadolinium-chelating contrast material, conventional $\mathrm{T}_{1}$-weighted MR images were obtained to complete the presurgical evaluation imaging session.

\section{Imaging Data Analysis}

All imaging data obtained from the conventional and functional imaging acquisitions were transferred to a workstation with commercially available software for further postprocessing and photographing. By viewing animations of the 40 images in each slice, the imaging data from the functional experiments were screened for motion. Parametric maps of brain activity were generated by applying a pixel-by-pixel temporal correlation analysis 
that was based on a correlation coefficient algorithm.[1] This algorithm correlates the time course data sets with generic reference functions that have a periodic "boxcar" waveform. Cross-correlating a pixel's time series with a reference wave form can effectively remove artifactual signals such as cerebrospinal fluid or brain pulsatility, which are randomly timed with respect to the stimulation paradigm. As a time reference, we applied a boxcar waveform, which was shifted by 2 to 6 seconds (one to two images) in the second sequence to account for the temporal low-pass filtering that occurs as a result of a hemodynamic response. Those pixels in which the mean of the MR signal in activation images significantly exceeded the mean of the resting images, with a probability value of less than 0.001 according to the Student's t-test, were used for viewing the functional maps. Generated functional maps of regional brain activity were displayed in pseudocolor, scaled according to statistical significance, and overlaid directly on the gray-scale high-resolution $\mathrm{T}_{1}$-weighted $\mathrm{MR}$ images obtained at the same anatomical location. The exact anatomical location of activated areas relative to the central sulcus was estimated in each slice by cross referencing the functional slices with the sagittal localizer images. The entire postprocessing procedure required approximately 15 to 20 minutes, and the functional maps generated were printed and available, together with the rest of the structural MR imaging acquisitions, for discussion with the neurosurgery colleagues prior to the surgical procedure.

\section{Techniques of Intraoperative Stimulation Mapping and Tumor Localization}

All patients underwent surgery after induction of general anesthetic in which short-acting relaxants and propofol were used but not barbiturates. Mapping techniques were performed according to Berger and Ojemann. [5] Intraoperative ECS was performed in all patients by using a portable stimulator. The stimulation was performed using a bipolar probe consisting of electrodes $1 \mathrm{~mm}$ in diameter and spaced $5 \mathrm{~mm}$ apart. In cases in which the motor cortex was thought to be beyond the craniotomy borders, stimulation was performed using a four-electrode strip introduced into the subdural space, as shown in Fig. 1. Brief trains of bipolar square-wave pulses of 1 to $4 \mathrm{msec}$ at 50 to $60 \mathrm{~Hz}$ were used, beginning with a current of $2 \mathrm{~mA}$. The current varied from $2 \mathrm{~mA}$ to as high as $10 \mathrm{~mA}$. If no responses were elicited at the 2-mA level, the current was gradually increased in 0.5 to $1 \mathrm{~mA}$ increments. A trained observer was present to monitor carefully the responses of the patient's hands, fingers, face, and feet resulting from each stimulation. Stimulation was immediately stopped as soon as motor responses occurred. In two cases focal motor responses did not cease spontaneously, and intravenous diazepam and short-acting barbiturate were given. In three patients, (Cases 1, 2, and 8) additional standard electrocorticography (ECoG) was performed using strips and/or grids to attempt maximal resection of epileptogenic tissue.

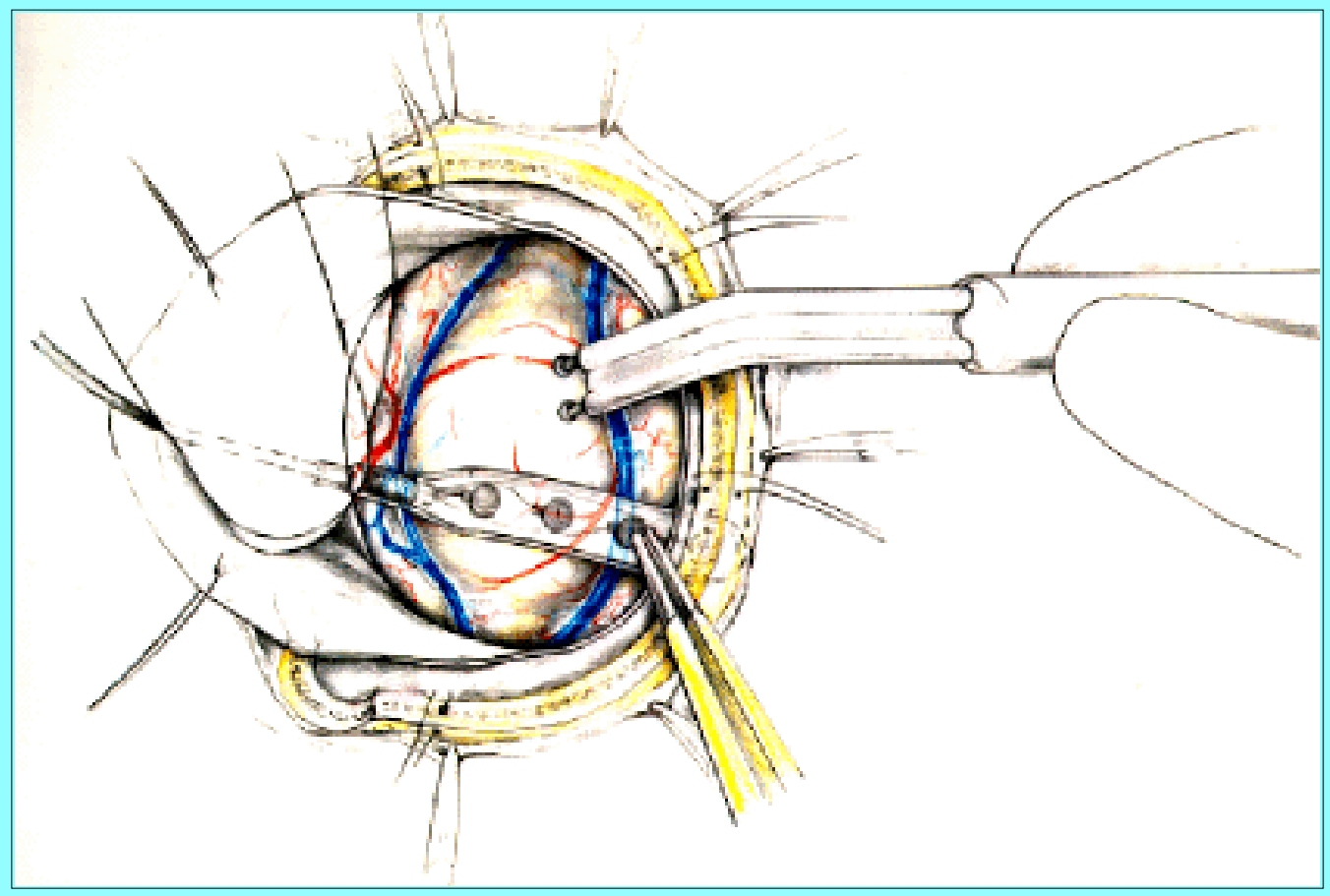

Fig. 1. Artistic illustration depicting the intraoperative cortical stimulation in a patient with a 
low-grade astrocytoma involving the precentral gyrus (such as in the patient in Case 2). Stimulation was performed using bipolar probe and strip electrodes to identify the motor cortex.

Intraoperatively, anatomical structures were identified, and tumor localization could be documented in all cases by using sonography in which a 7.5-MHz linear-array transducer was used. The sonography apparatus provided a two-dimensional intraoperative real-time image of brain parenchyma as well as color-coded flow imaging of the cerebral vessels. Topographic relations between tumor borders and primary motor and premotor cortices were elucidated and compared with fMR imaging findings before direct ECS was initiated. We considered it a "good correlation" with fMR imaging findings if motor responses were obtained after the first stimulation attempt in the suspected motor cortex or after further attempts within $20 \mathrm{~mm}$ from the first chosen cortical site.

\section{SOURCES OF EQUIPMENT}

The whole-body MR system, Advantage Windows software, and the "double-doughnut" system mentioned in the Discussion and available in our hospital were acquired from General Electric Medical Systems (Milwaukee, WI). The workstation used for processing the imaging data was obtained from Sun Microsystems, Inc. (Palo Alto, CA). Both the portable stimulator (model OCS-1) and the bipolar probe (model OCS-P) were obtained from Radionics (Burlington, MA). The four-electrode strip was purchased from AD-Tech Medical Instrument Corporation (Racine, WI) and the sonography apparatus and linear-array transducer from B \& K Medical (Norderstedt, Germany).

\section{RESULTS}

Functional MR imaging demonstrated signal intensity changes in the range of 2 to $5 \%$ between rest and activation conditions in all patients ( $\mathrm{p}=0.001$, Student's t-test). In seven patients two or more activation sites were demonstrated on fMR imaging. Four different fMR imaging activation, or "reorganization patterns," were demonstrated in the eleven patients as follows: 1) contralateral primary motor area (MI) in nine patients; 2) contralateral premotor area (MII) in four patients; 3) ipsilateral MI in two patients; and 4) ipsilateral MII in four patients (Table 2).

\begin{tabular}{|cc|}
\hline & TABLE 2 \\
REORGANIZATION PATTERNS OF CORTICAL MOTOR AREASACCORD NG TO \\
FMR IMAGNG ACTMATION SITES IN 11 PATIENTS WITH CENTRAL TUMORS \\
\hline \hline Site & No. of Patierts \\
\hline contralateral primary motor area & 9 \\
ipsilateral primary motor area & 2 \\
contralateral premotor area. & 4 \\
ipsilateral premotor area & 4 \\
\hline x There may be more than one fMRI activation site in seven patients. \\
\hline
\end{tabular}

In nine $(82 \%)$ of 11 patients, the anatomical fMR imaging localization of motor areas (MI or MII) could be verified by intraoperative ECS (Table 1). In seven patients in whom the lesion had compressed and shifted the primary motor cortex (MI) according to fMR imaging findings, a response after stimulation could be elicited. In addition, fMR imaging activation of reorganized motor areas other than MI (contralateral MII or supplementary motor area [SMA]) could be verified intraoperatively in three patients (Cases 5, 6, and 9). In two patients (18\%) there was no anatomical correlation between intraoperative ECS findings and motor areas observed on fMR images (Cases 7 and 8 ); in one of those (Case 8) no motor response could be elicited. This patient showed fMR imaging activation of ipsilateral MI and contralateral MII, which were mainly located deep within the sulci.

Eight patients underwent total and one subtotal macroscopic removal of the tumor. In three patients a partial removal was performed due to the tumor's involvement with motor areas, which were delimited with intraoperative stimulation. Postoperative findings included no motor deficit after surgery (six patients), improvement of preoperative deficit after tumor removal (one patient; Case 1), and transient focal deficits (three patients experienced motor deficits and one presented with a transient dysphasia). All patients recovered within 48 hours after surgery. 
The following cases illustrate the different patterns of motor activation in fMR imaging, emphasizing the possible reorganization of the motor cortex in patients with tumors close to or involving the central areas who underwent intraoperative ECS.

\section{ILLUSTRATIVE CASES}

\section{Case 4. Activation of Contralateral Primary Motor Area and Ipsilateral Premotor Area}

This 50-year-old right-handed man had a one-year history of headaches. Two weeks before admission, the patient developed a progressive left hemiparesis and sleepiness. His electroencephalography status was normal, and there was no history of seizures. The scalp electroencephalography showed a right central slowing. A suspicion of lung carcinoma raised during a radiological evaluation was confirmed preoperatively with computerized tomography (CT) scans of the thorax. A $\mathrm{T}_{1}$-weighted $\mathrm{MR}$ image revealed a rim-enhancing necrotic lesion located in the right central region that laterally compressed, the central sulcus in its entire length (Fig. 2 left). The ${ }^{18}$ F-fluoro-2-deoxyglucose positron emission tomography ( $\left.{ }^{18} \mathrm{~F}-\mathrm{FDG}-\mathrm{PET}\right)$ demonstrated a high metabolic lesion in the right parietal lobe in and around the mass. The fMR imaging of motor cortex during alternating conditions between rest and clenching of the left fist showed statistically significant $(p<0.001)$ contralateral activation along the central sulci that corresponded to the parenchymal right primary motor hand area. In addition, activation of the ipsilateral (left) premotor area could be demonstrated (Fig. 2 right). Intraoperatively, the lesion could be localized at a 5-mm depth by using ultrasound. The central sulcus and central gyrus appeared to be compressed anteriorly, adjacent to the anterior lateral border of the mass. During intraoperative ECS of the expected right motor cortex, movements of the left hand were observed after the first attempt in which bipolar square-waves of $3 \mathrm{msec}$ at $50 \mathrm{~Hz}$ and a current of $6 \mathrm{~mA}$ were used. After total macroscopic resection of the lesion, stimulation was repeated and motor responses remained unchanged. Postoperatively, the patient experienced a transitory deterioration of the left hemiparesis, which improved rapidly during the following days.
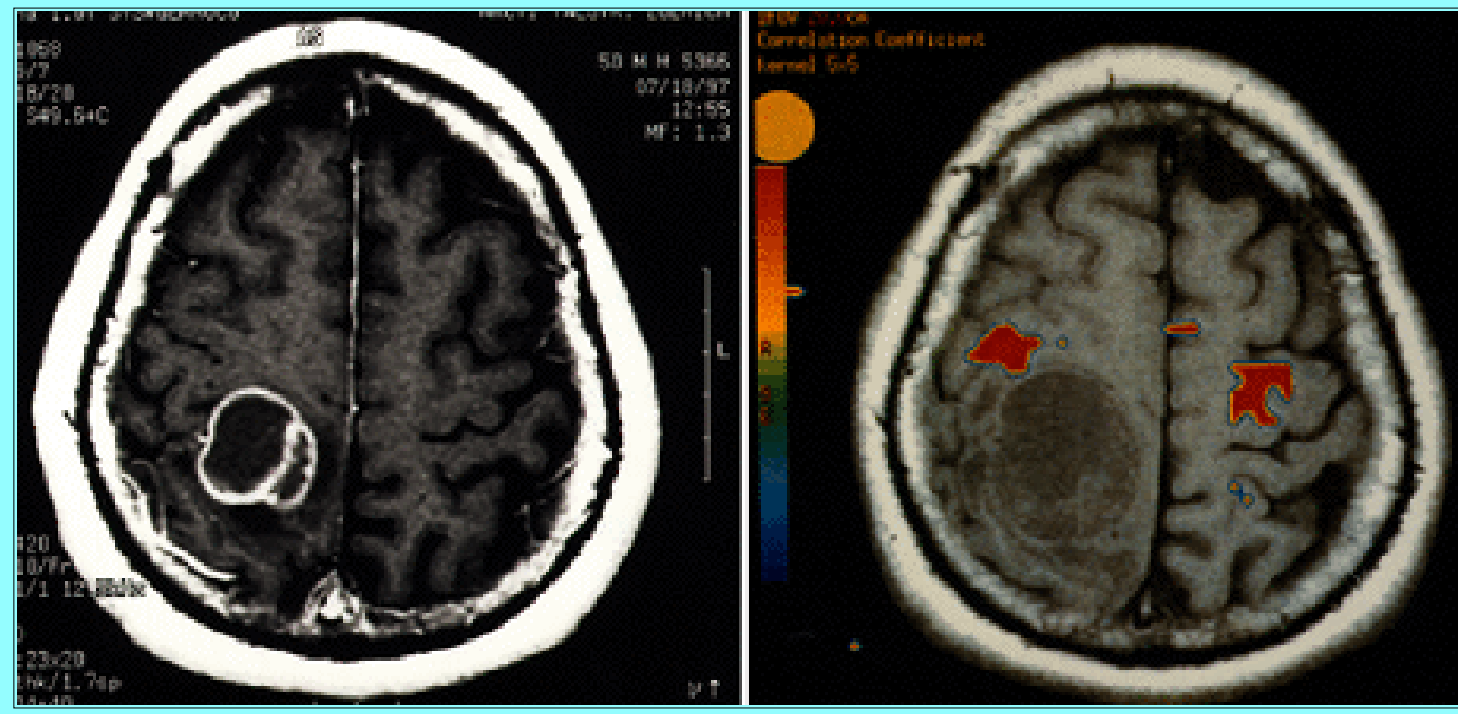

Fig. 2. Case 4. Left: Axial $\mathrm{T}_{1}$-weighted $M R$ image obtained after gadolinium administration showing a rim-enhancing necrotic metastasic lesion in a 50-year-old patient with lung carcinoma. The mass is located in the right central region compressing, laterally, the central sulcus that is difficult to identify in its entire length. Right: The fMR image of motor cortex during alternating conditions between rest and clenching of the left fist showing statistically significant $(\mathrm{p}<0.001)$ activation along the contralateral central sulci that corresponds with to parenchymal primary motor hand areas and, in addition, activation of ipsilateral (left) premotor area and, to a lesser degree, the SMA. During intraoperative cortical stimulation of the expected motor cortex, movements of the left hand were observed. 
This 32-year-old right-handed woman had a 5-year history of simple partial seizures. Her daily seizures began with numbness in the left arm and progressed to clonic movements of the left hand and arm. In 1993 a tumor in the left parietal lobe was found and subtotally removed. The histopathological diagnosis was oligoastrocytoma (WHO Grade II). After surgery she remained seizure free, and no focal neurological deficits were present. In April 1998, after giving birth to her third child, the seizures increased in frequency and became intractable. A $\mathrm{T}_{1}$-weighted MR image revealed a mildly enhancing recurrent low-grade astrocytoma that infiltrated the right precentral gyrus and the entire parietal lobe. The central sulcus and adjacent cortical areas were indistinguishable from the tumor mass (Fig. 3 upper left). The ${ }^{18}$ F-FDG-PET demonstrated an increased subcortical regional glucose uptake into the tumor (Fig. 3 upper right). Two slices from the multislice fMR imaging experiment during self-paced opening and closing of the left fist demonstrated statistically significant activation $(\mathrm{p}<0.001)$ in the ipsilateral central, postcentral, and premotor cortical areas, as well as in the contralateral premotor areas along the superior frontal sulcus and the precentral sulcus (Fig. 3 lower left and right). No activation was detected in the contralateral primary motor cortex, which was infiltrated by the tumor. Based on clinical and radiological follow-up evaluation, we decided that the patient should undergo reoperation, which was performed in November 1997. Intraoperatively, after ultrasonographic localization of the tumor and identification of anatomical structures, we could not elicit any motor response during stimulation of the central region. Tumor infiltration into the postcentral gyrus was evident, and the precentral gyrus was clearly shifted anteriorly. Electrical cortical stimulation was performed using a four-electrode strip introduced in the subdural space beyond the anterior craniotomy border in the superior frontal gyrus. Movements of the left hand could be obtained with a current of $8 \mathrm{~mA}$ at $50 \mathrm{pulses} / \mathrm{second}$. Analysis of these findings demonstrated that the premotor area along the superior frontal gyrus was clearly involved in the motor cortical function in this particular patient with a slowly growing tumor in the central region (Fig. 3 lower left).
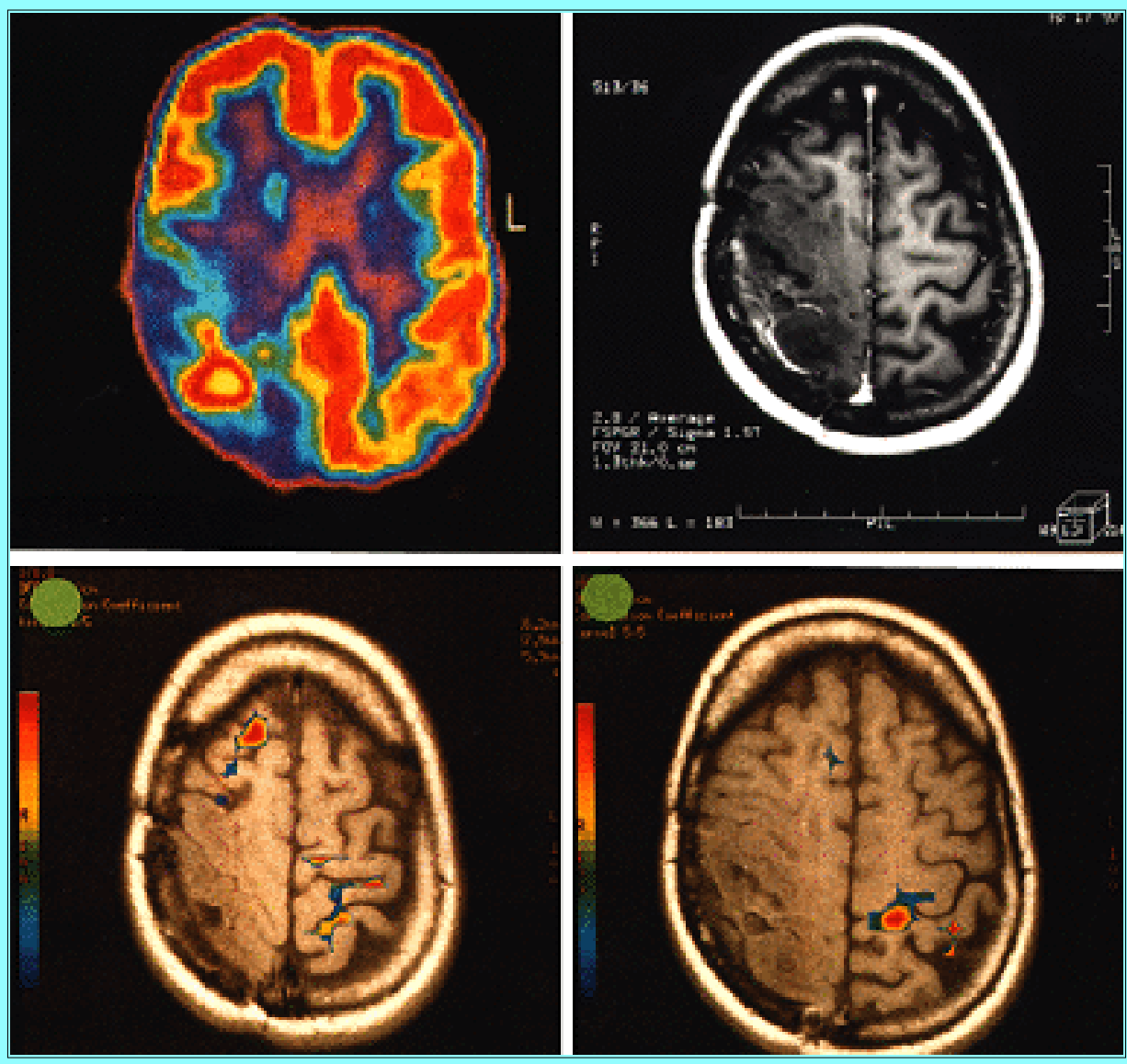

Fig. 3. Case 6. Upper Left: Axial $\mathrm{T}_{1}$-weighted $\mathrm{MR}$ image obtained after gadolinium administration of a 32-year-old woman showing a mildly enhancing recurrent low-grade astrocytoma infiltrating the right precentral gyrus and the entire parietal lobe. The central sulcus and adjacent cortical areas are indistinguishable from the tumor mass. Upper Right: The ${ }^{18}$ F-FDG-PET demonstrating an increased regional glucose uptake into the tumor. Lower Left and Right: Two slices from the multislice fMR 
imaging experiment during self-paced opening and closing of the left fist showing statistically significant activation $(\mathrm{p}<0.001)$ in the ipsilateral central, postcentral, and premotor cortical areas, as well as in the contralateral premotor areas along the superior frontal sulcus and the precentral sulcus. No activation was detected in the contralateral primary motor cortex, which was infiltrated by the tumor. During stimulation of the premotor area along the superior frontal gyrus, movements of the left hand were observed.

\section{Case 9. Activation of Contralateral Primary Motor Area (Hand and Foot)}

This 38 year-old man had an 11-year history of simple partial seizures. In 1988 a right frontal low-grade astrocytoma was removed. The patient remained free of seizures in spite of evidence suggesting tumor recurrence in the follow-up MR imaging studies since 1993. Since the beginning of 1998, his headaches and secondary generalized tonic-clonic seizures became frequent. Examination of the MR images demonstrated a recurrence of the tumor localized in the right middle frontal gyrus with infiltration of the precentral cortical region (Fig. 4 upper left). The ${ }^{18}$ F-FDG-PET demonstrated a high metabolism in the tumor. Functional MR imaging of motor cortex during alternating rest and fist-clenching conditions of the left hand revealed statistically significant $(\mathrm{p}<0.001)$ activation in the contralateral primary motor cortex that corresponded with the hand representation area along the central sulcus, which was compressed posteriorly at the posterior border of the tumor (Fig. 4 upper right). Functional MR imaging of the motor cortex during alternating conditions between rest and flexion-extension of the toes on the left foot demonstrated an area of activation in the paracentral lobule that corresponded to the parenchymal primary motor foot area (Fig. 4 lower). The patient underwent reoperation, and a partial removal of the tumor was performed. Analysis of the histopathological findings demonstrated a malignant progression to anaplastic astrocytoma (WHO Grade III). After localization of the tumor and its cystic components by using intraoperative sonography, direct ECS was performed in the lateral and mesial precentral gyrus. Movements of the left hand could be elicited when the posterior part of the tumor was stimulated, showing an excellent correlation with activation demonstrated on fMR imaging. In addition, movement of the left foot could be observed during ECS in the expected cortical region (Fig. 4 upper right and lower). The tumor-infiltrated motor cortex was not resected, and postoperatively the patient experienced no motor deficit.
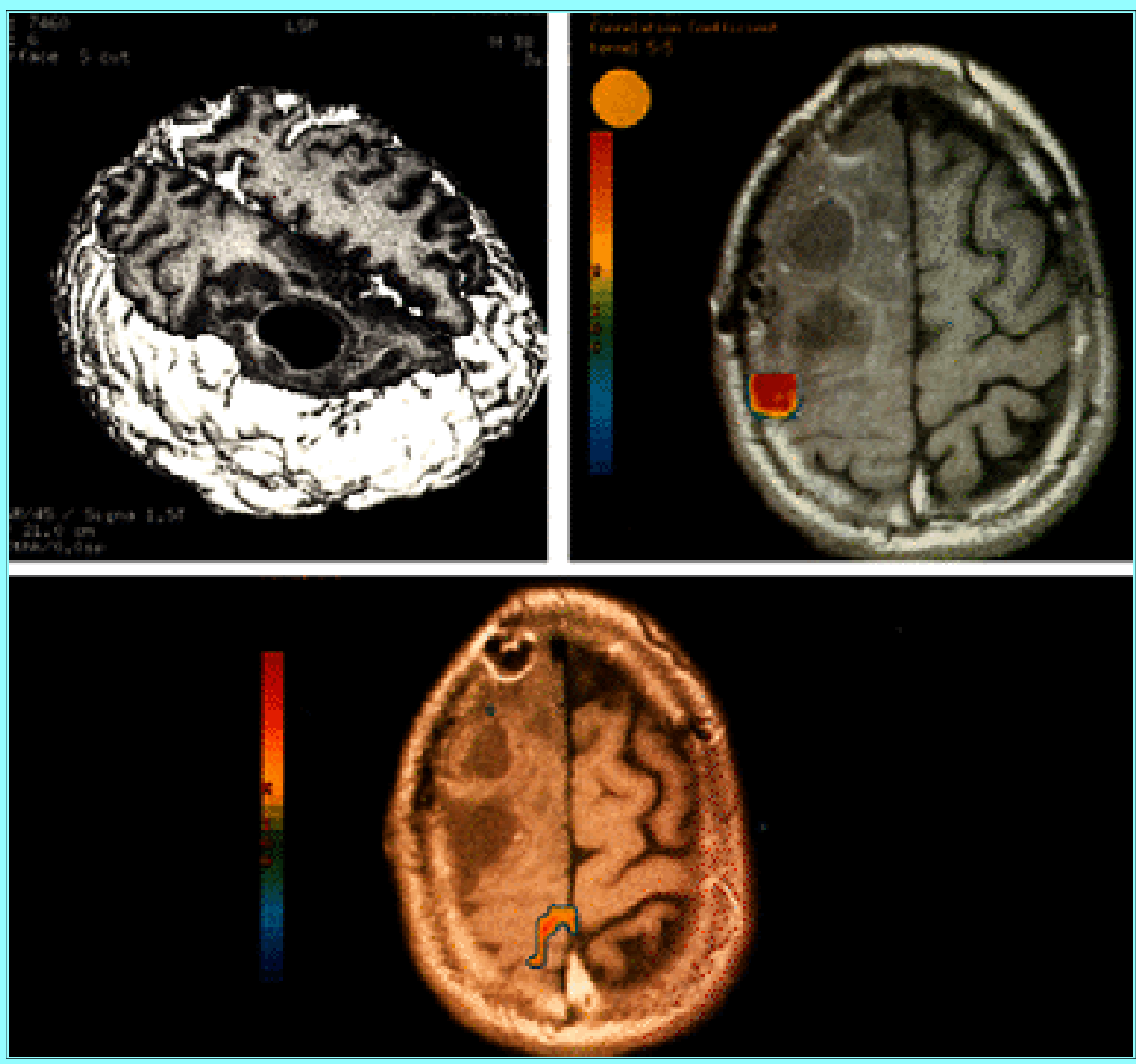
Fig. 4. Case 9. Upper Left: Axial section through a volume-rendered MR image of the brain reconstructed from a three-dimensional RF-spoiled gradient echo acquisition in a 38-year-old man with recurrent oligodendroglioma in the right middle frontal gyrus. The superior frontal sulcus is compressed medially by the cystic component of the tumor, and the precentral cortical region seems infiltrated. Upper Right: Functional MR image of motor cortex during alternating rest and fist clenching conditions of the left hand revealing statistically significant $(\mathrm{p}<0.001)$ activation in the contralateral primary motor cortex that corresponds with the hand representation area along the central sulcus at the posterior border of the tumor. Lower: Functional MR image of motor cortex during alternating conditions between rest and flexion-extension of the toes of the left foot demonstrating an area of activation in the paracentral lobule that corresponds with the parenchymal primary motor foot area. Good correlation during cortical stimulation of both areas was demonstrated intraoperatively.

\section{Case 11. Activation of Contralateral Primary Motor Area}

This 69-year-old left-handed woman had a 4-month progressive history of aphasia, headaches, and sleepiness. Magnetic resonance imaging revealed a tumor (glioblastoma multiforme) involving the precentral region of the left middle frontal gyrus (Fig. 5 left). Functional MR imaging of motor cortex during the right-fist clenching task revealed significant activation ( $<<0.001$ ) in the primary motor hand area of the contralateral hemisphere just anterior to the central sulcus, which was compressed superiorly by the tumor (Fig. 5 right). The tumor was partially removed via a temporal approach guided by intraoperative ultrasound. A right facial-brachial motor response could be elicited after ECS of the suspected MI according to the fMR image findings.

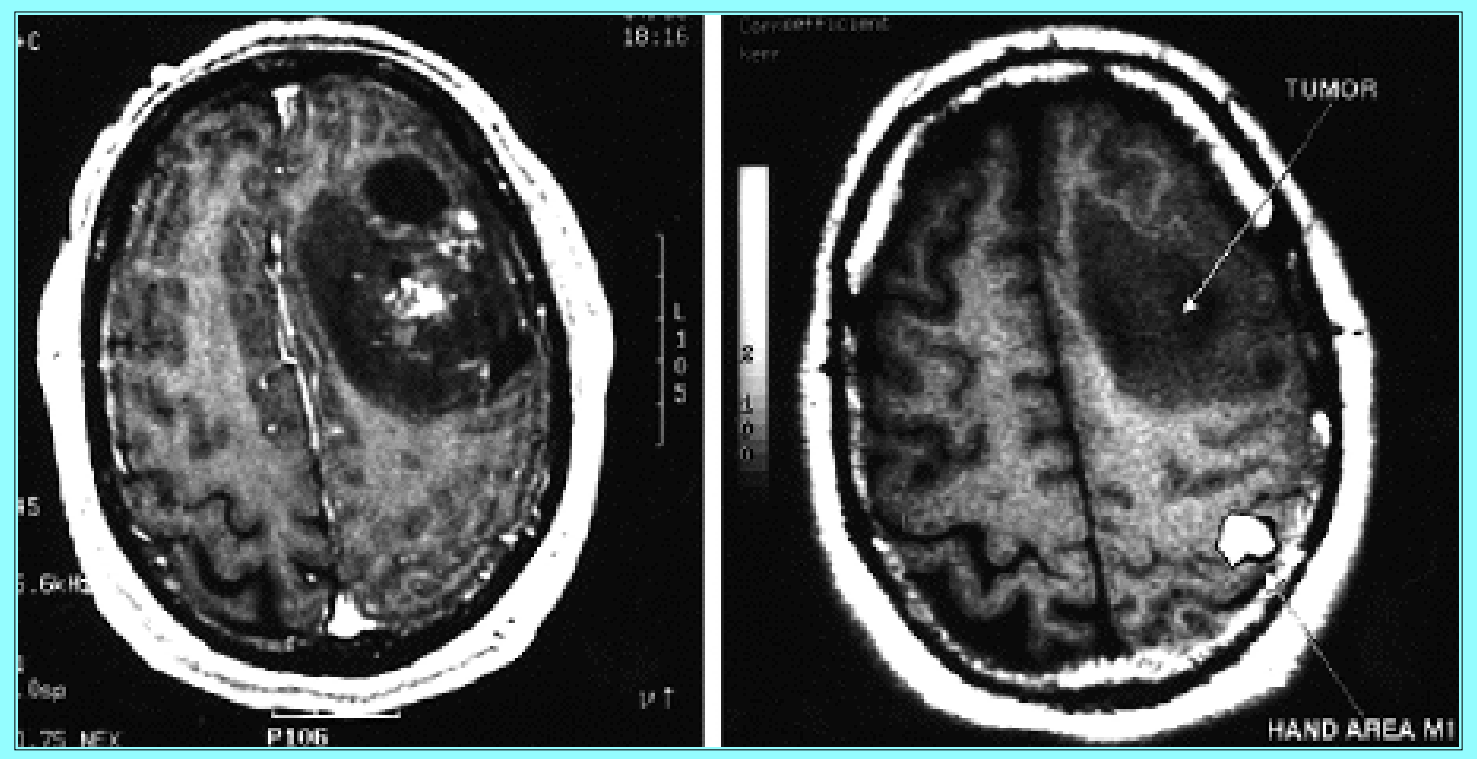

Fig. 5. Case 11. Left: Axial $\mathrm{T}_{1}$-weighted $\mathrm{MR}$ image obtained after gadolinium administration in a 69-year-old woman with glioblastoma multiforme involving the precentral region of the left middle frontal gyrus. Right: Functional MR image of motor cortex during clenching of the right fist revealing significant activation $(\mathrm{p}<0.001)$ in the primary motor hand area of the contralateral hemisphere just anterior to the central sulcus which was compressed superiorly by the tumor. Good correlation between fMR imaging findings and intraoperative ECS could be demonstrated.

\section{DISCUSSION}

\section{Correlation Between fMR Imaging and Electrophysiological Intraoperative Findings}

Since the beginning of this century, the use of ECS has been considered the gold-standard method to localize eloquent areas in the brain.[7,32,34,41] The introduction of diagnostic imaging methods in clinical practice encouraged the attempt to correlate images, primarily computerized tomography, with functional regions of the brain.[14,20] One decade later, in 1990, Berger, et al.,[3] published the first study in which MR imaging data were 
correlated with motor cortex brain mapping. The authors accurately identified the central sulcus and the precentral (motor) gyrus in nine patients, localizing the pair of transverse (central) sulci easily seen on high-vertex axial MR images. These types of preoperative studies allowed for a better understanding of anatomical structures surrounding the infiltrating intrinsic tumors, and prompted better surgical strategies in order to achieve a maximal removal of the tumor at the same time preserving the functionally eloquent cortices essential for language, motor and somatosensory functions.[32] Because anatomical landmarks identified in high-resolution MR imaging do not guarantee that essential areas have not been resected, $[4,5,33]$ only the intraoperative identification of function assures a safe resection to minimize morbidity. In spite of the fact that the human sensorimotor cortex can also be localized intraoperatively by cortical surface recording of somatosensory evoked potentials (SSEPs), $[9,47,48]$ or, as has been more recently reported, in combination with magnetoencephalography, $[15,16]$ intraoperative ECS remains an easy, reliable, and safe method for functional localization of essential regions to maximize a safe resection of brain tumors.[4,32] We adopted to perform ECS routinely during resection of brain tumors involving central areas; we have done so by using a standardized anesthesia protocol consisting of short-acting relaxants and propofol but no barbiturates. In addition, intraoperative ECoG is a helpful tool, not only for resecting epileptogenic tissue surrounding tumors to accomplish seizure-free outcome but for identifying pathological tissue, the intraoperative visualization of which normally constitutes a challenge for the surgeon. In the series presented in this study, three (Cases 1, 2, and, 8) out of 11 patients underwent ECoG and ECS. In all cases, postresection ECoG demonstrated no epileptoform spikes in the cortex adjacent to the resection. These three patients remained seizure free at 6-month follow-up evaluation.

The introduction of fMR imaging early in this decade brought new perspectives to the overall evaluation of functional patterns of the human cortex.[1,2,21,31] This technique, which has better resolution in space and time (compared with other functional neuroimaging techniques such as PET and single photon emission CT), quickly found clinical applicability in neurosurgery.[24,39] For this reason, we have recently limited the use of ${ }^{18}$ F-FDG-PET studies to presurgical ictal and interictal evaluation of candidates for epilepsy surgery, as well as to assessment of brain tumor metabolism as represented by the patient in Case 6 (Fig. 3 upper right).

The basis of fMR imaging is that deoxyhemoglobin acts as an endogenous paramagnetic contrast agent, and therefore changes in its local concentration lead to an alteration in the $\mathrm{T}_{2}{ }^{*}$-weighted $\mathrm{MR}$ image signal.[31] During performance of cognitive tasks, neural activation within the cerebral cortex leads to a large increase in blood flow without an increase of similar magnitude in oxygen extraction.[13] This in turn causes a decrease in the capillary and venous deoxyhemoglobin concentrations, producing an increase in the $\mathrm{T}_{2}{ }^{*}$-weighted MR signal. Early experiences with this technique in functional imaging of the human visual cortex[2,31] and sensorimotor cortex[21] have encouraged its application in patients with brain lesions, especially as a noninvasive preoperative study for surgical planning.[12,15,17,18,29,36,37,50] More recently, our group[23] reported the application of fMR imaging in 12 patients with retrochiasmatic lesions who had undergone surgical treatment. In this study, Kollias, et al., demonstrated that fMR imaging can detect visual field defects that are not only caused by lesions that destroy the primary visual cortex but also by lesions that interrupt the visual pathway, creating a lack of sensory input. These findings can be used to corroborate the applicability of fMR imaging as a noninvasive presurgical study the assessment of cortical function, which has to be preserved or improved in patients undergoing surgical treatment.

In a further attempt to validate fMR imaging findings and to evaluate its applicability in neurosurgical strategies, we decided to perform a study in which we correlated activation sites on fMR imaging with intraoperative electrical stimulation of the motor cortex. In reviewing the literature, it is evident that most of the articles, in which correlation is reported between fMR imaging findings and ECS, are presented more as reports on case series than as studies with a standardized protocol (Table 3).[29,35-37,41,49-51] 
TABLE 3

STUDIES IN WHKH CORRELATION BETWEEN FMR IMAGNG AND ECS IS REPORTED*

\begin{tabular}{|c|c|c|c|c|c|}
\hline Authors \& Year & $\begin{array}{l}\text { Individuals } \\
\text { Studied 'w' } \\
\text { fMR Imaging }\end{array}$ & $\begin{array}{l}\text { Pts Who } \\
\text { Underwent } \\
\text { ECS }\end{array}$ & $\begin{array}{l}\text { Diagnosis } \\
\text { (n o. of pts.) }\end{array}$ & $\begin{array}{l}\text { Intraop } \\
\text { Localizabion } \\
\text { Method }\end{array}$ & Resuls \\
\hline $\begin{array}{l}\text { Yoursy et al., } \\
1995\end{array}$ & $\begin{array}{l}4 \text { healthy wolun- } \\
\text { teers; } 6 \text { pts }\end{array}$ & 5 & $\begin{array}{l}\text { astrocytoma (3); } \\
\text { cavernoma (3) }\end{array}$ & visual & $\begin{array}{l}\text { same location } \\
\text { in all cases }\end{array}$ \\
\hline $\begin{array}{l}\text { Puce, et al., } \\
1995\end{array}$ & $\begin{array}{l}6 \text { healthy wolun- } \\
\text { teers; } 4 \text { pts }\end{array}$ & $4 \dagger$ & $\begin{array}{l}\text { tumor (3); epi- } \\
\text { lepsyiEC (1) }\end{array}$ & visual & $\begin{array}{l}\text { good correspondence } \\
\text { of fMR \& ECS }\end{array}$ \\
\hline $\begin{array}{l}\text { Mueller, et al., } \\
\quad 1996\end{array}$ & $12 \mathrm{pts}$ & 3 & $\begin{array}{l}\text { AVM (1); astro- } \\
\text { cytoma (1); oli- } \\
\text { godendroglioma (1) }\end{array}$ & visual & $\begin{array}{l}\text { confirmation of fMRI } \\
\text { in all } 3 \text { cases }\end{array}$ \\
\hline $\begin{array}{l}\text { Pujol, et al., } \\
1996\end{array}$ & $\begin{array}{l}25 \text { health y wolun- } \\
\text { teers; } 4 \text { pts }\end{array}$ & 4 & $\begin{array}{l}\text { astrocytoma (2) } \\
\text { metastasis (1); oli- } \\
\text { godendroglioma (1) }\end{array}$ & visual & $\begin{array}{l}\text { accurate correlation } \\
\text { in } 4 \text { cases }\end{array}$ \\
\hline $\begin{array}{l}\text { Yetkin, et al., } \\
1997\end{array}$ & $28 \mathrm{pts} \ddagger$ & 28 & $\begin{array}{l}\text { epilepsyiE (22); } \\
\text { tumor (5); nVM (1) }\end{array}$ & visual & $\begin{array}{l}\text { correlation within } \\
20 \mathrm{~mm} \text { in all pts }\end{array}$ \\
\hline $\begin{array}{l}\text { Pujol, et al., } \\
1998\end{array}$ & $50 \mathrm{pts}$ & 22 & ND & visual & $\begin{array}{l}100 \% \text { confirm ation } \\
\text { of fluR findings }\end{array}$ \\
\hline $\begin{array}{l}\text { Schulder, et al., } \\
1998\end{array}$ & $12 \mathrm{pts}$ & $7 \dagger$ & $\begin{array}{l}\text { meningioma (4); } \\
\text { GBM (2); oligoden- } \\
\text { droglioma (1) }\end{array}$ & $\mathrm{FSC}$ & $\begin{array}{l}\text { confirmation } \\
\text { of fluR in all } \\
\text { procedures }\end{array}$ \\
\hline $\begin{array}{l}\text { present series, } \\
1999\end{array}$ & $11 \mathrm{pts}$ & 11 & $\begin{array}{l}\text { astrocytoma Grades } \\
\text { IIII (4); GBM (2); } \\
\text { metastasis (2); me- } \\
\text { ningiom a (1); oligo- } \\
\text { dendrogliom a (2) }\end{array}$ & $\begin{array}{l}\text { ultra- } \\
\text { sound }\end{array}$ & $\begin{array}{l}82 \% \text { correlation of } \\
\text { fluR and } \mathrm{ECS} \\
\text { findings }\end{array}$ \\
\hline \multicolumn{6}{|c|}{ 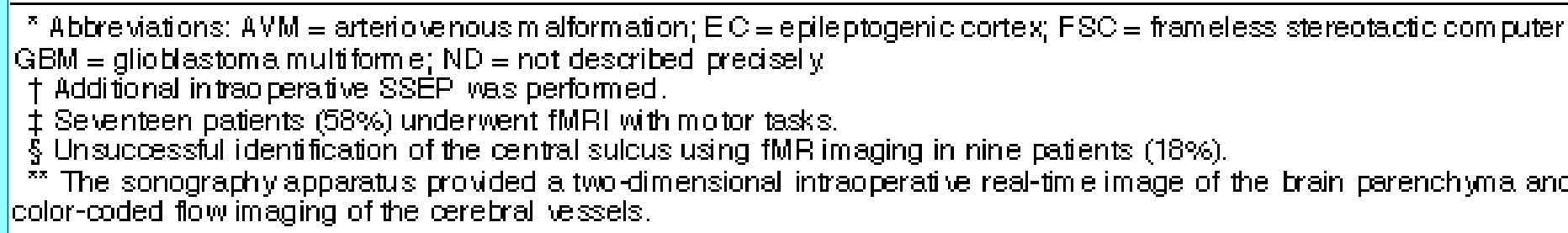 } \\
\hline
\end{tabular}

In addition, the patients included in most of the studies were not consecutive, were sometimes selected from a larger patient series, or were simply compared with healthy volunteers. Such reports provided us with more of an anecdotal impression and lead us to question the reliability and consequences of fMR imaging studies in patients with lesions in the central region who have undergone presurgical evaluation. On the other hand, because most of the studies were designed and published by neuroradiologists and neurophysiologists, we believe that many important neurosurgery-related aspects were emphasized. In 1995, Yoursy, et al.,[50] reported a study that included four healthy volunteers and six patients who harbored lesions close to or in the precentral gyrus. In five patients who had undergone intraoperative electrical stimulation to correlate fMR imaging findings, the authors reported that "hand area was found to be the same with both techniques." In another study reported by the same group,[51] eight patients underwent fMR imaging and ECS for localization of the central sulcus by using the central vein as anatomical landmark. Yetkin, et al.,[49] evaluated the "spatial specificity" of fMR imaging by comparing it with intraoperative electrocortical mapping in 28 patients and reported a 100\% correlation. The same group published a study in which motor-task fMR imaging was performed in 10 patients; in this series, only three of the 10 patients underwent ECS and the authors reported "confirmation of fMR imaging findings."[29] Puce and colleagues[35] have compared the sensorimotor activation in fMR imaging with the location of sensorimotor cortex by using SSEPs elicited by electrical median nerve stimulation and ECS of the motor cortex in four patients. The patients included in this report were candidates for epilepsy surgery and underwent chronic ECoG, as well as ECS and SSEP monitoring in which long-term multicontact grids or strips were used. The authors stated that "electrical stimulation of the motor nerve (SSEPs) was not an optimum stimulus and produced little activation in the controls;" nevertheless, a good correspondence of motor areas identified by fMR imaging and ECS was reported in all four patients. Pujol and associates[37] evaluated 50 consecutive surgical candidates with central lesions. In nine (18\%) of 50 patients preoperative identification of the central sulcus was unsuccessful, and a subgroup of 22 patients underwent ECS for validation of fMR imaging findings; nevertheless, the authors reported confirmation of fMR 
imaging in $100 \%$ of the cases in which the tumor was used as a landmark for intraoperative identification of the sensorimotor cortex. Such an absolute conclusion ("100\% confirmation") might confuse the neurosurgical community, because cortical mapping findings in patients in whom fMR imaging was unsuccessful were not obtained or at least not reported. We believe that conclusions in such a validation study (with a gold-standard method) must include not only the cases in which ECS was not conclusive but also those in which fMR imaging did not demonstrate any localization of motor areas. Finally, Schulder, et al.,[41] have recently reported a study in which fMR imaging findings are compared with conventional brain mapping techniques in 11 patients. These authors reported that accurate registration of the sensorimotor cortex, as determined on fMR imaging, was confirmed in each procedure in which brain mapping was performed (SSEPs in six patients, ECS in one patient, and both methods in six patients).

We decided to study a consecutive series of patients with tumors close to or involving the central region to avoid bias resulting from the selection process. In our study, which was limited to the examination of the motor function, a good correlation between brain mapping techniques and fMR imaging was demonstrated in $82 \%$ of the patients, a figure not as high as those reported in the other studies previously mentioned (Table 3). Considering possible shifts of the sensorimotor cortex that might complicate the identification of gyri, sulci, and other anatomical landmarks such as the tumor lesion itself, we believe that studies conducted to validate fMR imaging must include intraoperative localization or navigation methods in addition to the visual topographic identification recorded by the surgeon. To our knowledge, only in the study by Schulder, et al., [41] and in our study, has intraoperative navigation technology been used to identify the lesion and to infer the localization of the sensorimotor cortex before performing brain mapping (Table 3). Schulder, et al., applied a frameless navigation computer, and we used sonography intraoperatively because of its advantage as a real-time localization method. In our center, the experience with the interventional MR imaging system or so-called "double doughnut system" might in the near future encourage the development of protocols to achieve real-time fMR image-guided surgery of lesions involving the sensorimotor cortex.[22] This new application of fMR imaging technology, nevertheless, has to be validated using the gold-standard brain mapping methods, such as ECS or SSEP monitoring before its introduction into the surgical routine. In addition, many known shortcomings and methodological issues must be taken into account when considering its applicability as a method offering advantages over the safe, easy, and reliable existing intraoperative mapping techniques.

Preservation of function is the main goal in the surgical treatment of patients with brain tumors close to or invading the sensorimotor cortex. Preoperatively fMR imaging allows better planning of surgical strategies and approaches. In addition, the benefits of surgery and possible attendant deficits can be objectively discussed with patients and relatives. On the other hand, surgical treatment of patients who suffer from intractable epilepsy or who present with seizures as manifestations of lesions, regardless of the size or histology, can undergo better preoperative evaluation to achieve optimum quality of life. The indication of ECoG or resection of epileptogenic tissue surrounding the lesion might be more easily considered if the patient undergoes preoperative fMR imaging. In our series, no patient sustained irreversible postoperative deficits; nevertheless, three patients sustained temporary deterioration of motor or language functions in the immediate postoperative period. These transient deficits could have been caused by intraoperative manipulation or decompression mechanisms; however, we believe that they might be easily prevented if a more careful study of preoperative fMR imaging findings is performed to consider better surgical strategies. In addition, fMR imaging played an important role in the decision making and approach, especially for patients in whom partial (Cases 9-11) or subtotal (Case 6) resection was performed. An advantage of fMR imaging over conventional brain mapping techniques is the identification of deep functional structures, which alert the surgeon to manage carefully the cortical, subcortical, and deep structures that might cause unexpected functional deterioration if damaged intraoperatively. In comparison with other techniques of functional imaging, such as PET or magnetoencephalography, fMR imaging allows a direct overlay onto high-resolution anatomical MR images. This permits better surgical planning than PET images that are superimposed on MR images, as is done in many centers. Because MR systems are more likely to be available in many institutions, a better understanding and validation of fMR imaging will be more easily performed by neurosurgeons who treat tumors located close to or within eloquent areas. Regardless of the enthusiasm arising from fMR imaging techniques in the preoperative 
evaluation, neurosurgeons have to be aware that: 1) fMR imaging is an indirect indicator of cerebral activation, because it measures changes in regional cerebral blood flow (rCBF) and not neuronal activity itself, such as is accomplished by magnetoencephalography; $[2,15,24,31] 2$ ) changes in blood oxygenation are characterized by a spatial and temporal dispersion that may cause errors in the accurate localization of activated areas (such as nonparenchymal deoxyhemoglobin changes in intraparenchymal capillaries or sulcal veins);[24,51] and 3) emerging functional imaging techniques or new applications of these have to be evaluated and validated objectively with gold-standard brain mapping techniques that are still considered safe and accurate to avoid neurological deficits or postoperative deterioration in patients undergoing removal of central lesions.

\section{Reorganization of Cortical Motor Cortex}

The results of this study clearly indicate that reorganization of the cortical motor cortex constitutes an important phenomenon, which might explain the diversity of motor deficits and different postoperative clinical findings in patients who harbor tumors close to or involving the primary motor areas. As shown in Table 2, we observed four different fMR imaging activation patterns during movements of the contralateral hand (or foot). Rao and coworkers[38] have reported that simple, self-paced finger movements activate the contralateral primary motor cortex, whereas complex, self-paced movements elicit functional changes in the contralateral (and occasionally ipsilateral) primary cortex (MI) as well as the SMA, the premotor cortex (MII) in both hemispheres, and the contralateral somatosensory cortex. In addition, motor ideation (without movement) activates the SMA and, to a lesser degree, the MII but not the MI.[21,38] According to our observations, in patients with slow-growing tumors, such as Cases 1,2, and 6, activation of cortical motor areas other than MI may have larger cortical representation during the performance of motor tasks. Our observations lead to the hypothesis that if MI is significantly impaired due to tumor infiltration or compression, the MII, SMA, or even ipsilateral cortical motor areas (MI) can assume the principal role for complex motor movements, which may mask expected neurological deficits. If signs of cortical reorganization or plasticity are present, postoperative functional outcome might become unpredictable.

In the pioneer studies of Brodmann[7] in 1909, he divided the agranular motor cortex into two regions: namely Areas 4 and 6 . Since this study, these cortical motor regions have been subdivided into progressively more detailed regions as a result of the availability of more sophisticated diagnostic techniques. Lüders, et al.,[26] and Matelli, et al.,[27] have described the approximate correspondence between the anatomical and functional cortical motor areas, which may overlap each other. Brodmann's[7] and Vogt's Area 4,[44] which is the anatomical so-called precentral gyrus, corresponds to the Area FA according to the study by Von Bonin and Bailey,[45] to Penfield and Boldrey's "motor strip" or primary motor area (MsI and MI),[34] and Matelli and coworkers' F1 region.[27] The premotor area (MII, M2 or MsII),[34] which corresponds with Area 6,[7] or Areas 6a-alpha and 6a-beta[44] and is functionally divided into a mesial and dorsolateral region. The premotor mesial region, or the area identified by Penfield and Boldrey as the medial premotor cortex, includes the SMA, the so-called SMA-proper (equivalent to the supplementary sensorimotor area[25]), and the pre-SMA (equivalent to the human supplementary negative motor cortex[26]). Because our observations were based on motor responses in patients in whom anesthesia had been induced and because sensory function was not evaluated, we preferred to use the term SMA instead of supplementary sensorimotor area, as suggested by some authors.[25]

Corticocortical connections of motor areas constitute the fundamental mechanism of cortical functional reorganization in the human brain. In a recent survey, Tanji[43] has described the flow of information through corticortical connections directed toward MI from areas such as the SMA, pre-SMA, cingulate motor area, dorsal and ventral premotor cortices, superior and inferior parietal association cortices, and the prefrontal cortex. Reinforcing these findings, cytoarchitectonic and receptor autoradiographic data, when combined with results from PET activation studies, provided evidence for similar anatomical and functional organization, as reported by Matelli, et al.[28] These authors observed in normal volunteers that proximal and distal arm movements are, to a large extent, segregated in the precentral motor cortex but not in the SMA. Their results indicate that: 1) distal movements (fingers and thumb) are associated with a significant rCBF increase in the contralateral sensorimotor cortex and 2) proximal movements (shoulder and whole arm) are accompanied by a significant rCBF increase in both the sensorimotor cortex and mesial motor areas contralateral to the arm that is being moved. In addition, an 
activation of the ipsilateral mesial motor areas was observed during whole-arm movements. Using fMR imaging techniques, Kim, et al.,[21] reported a hemispheric asymmetry in the functional activation of the human motor cortex during contralateral and ipsilateral finger movements, especially in right-handed patients.

The recovery of motor function, which indicated the complexity and interplay of neuronal activity among different motor areas, led to the study of "functional reorganization" and "plasticity" in patients with stroke,[10,46] brain injury,[8] and brain tumors.[42] Studying six patients after their recovery from hemiplegic stroke by using PET, Chollet, et al.,[10] demonstrated bilateral activation (rCBF increase) of MII, SMA, and insula during movement of the recovered fingers. The same group reported functional reorganization patterns (activation of anterior and posterior cingulate and prefrontal cortices) in 10 patients following striatocapsular infarction.[46] Since 1995, motor cortex plasticity has been studied by using fMR imaging techniques. Karni, et al.,[19] have reported a study in which the training of complex motor tasks such as rapid sequences of finger movements in normal adults, resulted in a new, more extensive representation (or reorganization) of the adult MI that may underlie the acquisition and retention of the motor skill. The overlapping representations, due to shared neural substrates that control hand movements in the human motor cortex, have also been an object of study in normal subjects who underwent fMR imaging, and these representations might facilitate plasticity mechanisms.[38,40]

Functional cortical reorganization and plasticity mechanisms in patients with brain tumors close to or involving cortical motor areas have been poorly studied. In a PET study Seitz, et al.,[42] reported that displacement of the rCBF increases from 9 to $43 \mathrm{~mm}$, occurring even outside of the precentral gyrus in the premotor or parietal cortex. In addition, the authors documented $\mathrm{rCBF}$ increases during movements of the affected hand in the SMA, right inferior frontal cortex, and "ectopic activations" in MII if displacement of the central sulcus was present. Among the studies presented in Table 3, cortical reorganization patterns based on fMR findings were neither precisely described nor discussed. Confirmation of "atypical" localization of the sensorimotor cortex or intraoperative mapping of regions other than the expected MI was not performed. Yousry, et al.,[50] mentioned in their study that in two of 10 cases (the authors did not specify if these cases were volunteers or patients), activation sites were observed ipsilateral to the hand that performed the motor task. Puce, et al.,[35] described in one illustrative case that fMR imaging motor activation was seen in two areas: on the precentral gyrus and in the bank of the central sulcus. In addition to attempting to correlate fMR imaging and ECS data, the strength of our study lies in the observations of different cortical reorganization patterns, as presented in Table 2. In seven of 11 patients, multiple activation sites were observed on fMR imaging, leading to the hypothesis that the function of the cortical motor areas, such as MI in patients with brain tumors, may play a less important role and is overtaken by other areas such as MII or SMA (contralateral or even ipsilateral to the motor task). The fMR imaging activation sites are summarized in Table 1. In four of 11 patients we observed an ipsilateral activation of MI or MII. In addition, we demonstrated in three patients (Cases 1-3) a significant activation of the SMA or so-called by Vogt Area 6a-beta[44] located in the mesial frontal gyrus. These observations might corroborate the findings described by Lüders, et al.[25,26] Taking into consideration the different predominance patterns of the different motor areas in our series of patients with brain tumors, we were encouraged to prove with intraoperative mapping techniques that stimulation of secondary or atypical motor areas could elicit motor responses. Case 6, the 32-year-old woman with a slowly growing tumor (oligoastrocytoma WHO Grade II) who suffered sensorimotor partial seizures without a motor deficit, provides a good example of plasticity and cortical reorganization. With the extension of such a lesion (Fig. 3 upper left), one would expect severe motor or sensory deficits. The findings on fMR imaging of activation of bilateral MII areas and the ipsilateral MI area (Fig. 3 lower left and right) explain the neurological status of the patient. During ECS, we obtained motor responses from the superior frontal gyrus that corresponded with the MII area, which probably assumed the main role in the motor function as consequence of a cortical reorganization phenomenon.

\section{CONCLUSIONS}

Functional MR imaging can aid in the objective evaluation of motor function in patients with lesions near to or involving the primary motor cortex. This technique can be performed as part of conventional examination in patients undergoing MR imaging for surgical treatment planning. Based on our experience, the correlation between fMR imaging findings and the results of direct electrical brain stimulation was high, although not $100 \%$. 
Functional MR imaging has contributed to changing the simplistic view that the motor cortical areas function separately from each other. In the near future, we believe that fMR imaging will become a broadly accepted and valuable tool for neurosurgeons in the assessment of patients with brain tumors in whom cortical reorganization patterns will demand a calmer, more careful preoperative evaluation. The validation and applicability of this and other new MR imaging-related techniques must, nevertheless, be kept within realistic and practical limits; the consequences of these techniques in the surgical approach and management of our patients must be carefully considered.

\section{Acknowledgments}

The authors thank Mr. Peter Roth for the artistic illustration (Fig. 1) and Mr. Roland Stillhard for the preparation of photographs.

\section{References}

1. Bandettini PA, Jesmanowicz A, Wonk EC, et al: Processing strategies for time-course data sets in functional MRI of the human brain. Magn Reson Med 30:167-173, 1993

2. Belliveau JW, Kennedy DN Jr, McKinstry RC, et al: Functional mapping of the human visual cortex by magnetic resonance imaging. Science 254:716-719, 1991

3. Berger MS, Cohen WA, Ojemann GA: Correlation of motor cortex brain mapping data with magnetic resonance imaging. J Neurosurg 72:383-387, 1990

4. Berger MS, Kincaid J, Ojemann GA et al: Brain mapping techniques to maximize resection, safety and seizure control in children with brain tumors. Neurosurgery 25:786-792, 1989

5. Berger MS, Ojemann GA: Techniques of functional localization during removal of tumors involving the cerebral hemispheres, in Loftus CM, Traynelis VC (eds): Intraoperative Monitoring Techniques in Neurosurgery. New York: McGraw-Hill, 1994, pp 113-127

6. Black PM, Ronner SF: Cortical mapping for defining the limits of tumor resection. Neurosurgery 20:914-919, 1987

7. Brodmann K: Vergleichende Lokalisationslehre der Grosshirnrinde in ihren Prinzipien dargestellt auf Grund des Zellenbaues. Leipzig: Barth, 1909

8. Cao Y, Vikingstad EM, Huttenlocher PR, et al: Functional magnetic resonance studies of the reorganization of the human hand sensorimotor area after unilateral brain injury in the perinatal period. Proc Natl Acad Sci USA 91:9612-9616, 1994

9. Cedzich C, Taniguchi M, Schäfer S et al: Somatosensory evoked potential phase reversal and direct motor cortex stimulation during surgery in and around the central region. Neurosurgery 38:962-970, 1996

10. Chollet F, DiPiero V, Wise RJ, et al: The functional anatomy of motor recovery after stroke in humans: a study with positron emission tomography. Ann Neurol 29:63-71,1991

11. Connelly A, Jackson GD, Frackowiak RSJ, et al: Functional mapping of activated human primary cortex with a clinical MR imaging system. Radiology 188:125-130, 1993

12. Cosgrove GR, Buchbinder BR, Jiang H: Functional magnetic resonance imaging for intracranial navigation. Neurosurg Clin North Am 7:313-322, 1996

13. Fox PT, Raichle ME: Focal physiological uncoupling of cerebral blood flow and oxidative metabolism during somatosensory stimulation in human subjects. Proc Natl Acad Sci USA 83:1140-1144, 1986 
14. Gado M, Hanaway J, Frank R: Functional anatomy of the cerebral cortex by computed tomography. J Comput Assist Tomogr 3:1-19, 1979

15. Gallen CC, Sobel DF, Waltz T, et al: Noninvasive presurgical neuromagnetic mapping of somatosensory cortex. Neurosurgery 33:260-268, 1993

16. Hund M, Rezai AR, Kronberg E: Magnetoencephalographic mapping: basis of a new functional risk profile in the selection of patients with cortical brain lesions. Neurosurgery 40:936-943, 1997

17. Jack CR, Thompson RM, Butts RK, et al: Sensory motor cortex: correlation of presurgical mapping with fMR imaging and invasive cortical mapping. Radiology 190:85-92, 1994

18. Kahn T, Schwabe B, Bettag M, et al: Mapping of the cortical motor hand area with functional MR imaging and MR imaging-guided laser-induced interstitial thermotherapy of brain tumors. Work in progress. Radiology 200:149-157, 1996

19. Karni A, Meyer G, Jezzard P, et al: Functional MRI evidence for adult motor cortex plasticity during motor skill learning. Nature 377:155-158, 1995

20. Kido DK, LeMay M, Levinson AW, et al: Computed tomographic localization of the precentral gyrus. Radiology 135:373-377, 1980

21. Kim SG, Ashe J, Hendrich K, et al: Functional magnetic resonance imaging of motor cortex: hemispheric asymmetry and handedness. Science 261:615-617, 1993

22. Kollias SS, Bernays R, Marugg RA, et al: Target definition and trajectory optimization for interactive MR-guided biopsies of brain tumors in an open configuration MRI system. J Magn Reson Imaging 8:143-159, 1998

23. Kollias SS, Landau K, Khan N, et al: Functional evaluation using magnetic resonance imaging of the visual cortex in patients with retroschiasmatic lesions. J Neurosurg 89:780-790, 1998

24. Kollias SS, Valavanis A, Golay XG, et al: Functional magnetic resonanace imaging of cortical activation. Int J Neuroradiol 2:450-472, 1996

25. Lüders HO: The supplementary sensorimotor area. An overview. Adv Neurol 60:1-16, 1995

26. Lüders HO, Dinner DS, Morris HH, et al: Cortical electrical stimulation in humans: the negative motor area. Adv Neurol 67:115-129, 1995

27. Matelli M, Luppino G, Rizzolatti G: Architecture of superior and mesial area 6 and the adjacent cingulate cortex in the macaque monkey. J Comp Neurol 311:445-462, 1991

28. Matelli M, Rizzolatti G, Bettinardi V, et al: Activation of precentral and mesial motor areas during the execution of elementary proximal and distal arm movements: a PET study. Neuroreport 4:1295-1298, 1993

29. Mueller WM, Yetkin FZ, Hammeke TA, et al: Functional magnetic resonance imaging mapping of the motor cortex in patients with cerebral tumors. Neurosurgery 39:515-521, 1996

30. Naidich TP, Valavanis AG, Kubik S: Anatomic relationships along the low-middle convexity: Part I. Normal specimens and magnetic resonance imaging. Neurosurgery 36:517-532, 1995

31. Ogawa S, Tank DW, Menon R, et al: Intrinsic signal changes accompanying sensory stimulation: functional brain mapping with magnetic resonance imaging. Proc Natl Acad Sci USA 89:5951-5955, 1992

32. Ojemann JG, Miller JW, Silbergeld DL: Preserved function in brain invaded by tumor. Neurosurgery 39:253-259, 1996 
33. Ojemann GA, Sutherling WW, Lesser RP, et al: Cortical stimulation, in Engel J (ed): Surgical Treatment of the Epilepsies, ed 2. Raven Press: New York, 1993, pp 399-414

34. Penfield W, Boldrey E: Somatic motor and sensory representation in the cerebral cortex of man studied by electrical stimulation. Brain 60:389-443, 1937

35. Puce A, Constable RT, Luby ML, et al: Functional magnetic resonance imaging of sensory and motor cortex: comparison with electrophysiological localization. J Neurosurg 83:262-270, 1995

36. Pujol J, Conesa G, Deus J, et al: Presurgical identification of the primary sensorimotor cortex by functional magnetic resonance imaging. J Neurosurg 84:7-13, 1996

37. Pujol J, Conesa G, Deus J, et al: Clinical application of functional magnetic resonance imaging in presurgical identification of the central gyrus. J Neurosurg 88:863-869, 1998

38. Rao SM, Binder JR, Bandettini PA, et al: Functional magnetic resonance imaging of complex human movements. Neurology 43:2311-2318, 1993

39. Rumeau C, Tzourio N, Murayama N, et al: Location of hand function in the sensorimotor cortex: MR and functional correlation. AJNR 15:567-572, 1994

40. Sanes JN, Donoghue JP, Thangaraj V, et al: Shared neural substrates controlling hand movements in human motor cortex. Science 268:1775-1777, 1995

41. Schulder M, Maldjian JA, Liu WC, et al: Functional image-guided surgery of intracranial tumors located in or near the sensorimotor cortex. J Neurosurg 89:412-418, 1998

42. Seitz RJ, Huang Y, Knorr U, et al: Large-scale plasticity of the human motor cortex. Neuroreport 6:742-744, 1995

43. Tanji J: The supplementary motor area in the cerebral cortex. Neurosci Res 19:251-268, 1994

44. Vogt C, Vogt O: Allgemeinere Ergebnisse unserer Hirnforschung. J Psychol Neurol 25:279-439, 1951

45. Von Bonin G, Bailey P: The Neocortex of Macaca Mulatta. Urbana: University of Illinois Press, 1947

46. Weiller C, Chollet F, Friston KJ, et al: Functional reorganization of the brain in recovery from striatocapsular infarction in man. Ann Neurol 31:463-472, 1992

47. Wood CC, Spencer DD, Allison T, et al: Localization of human sensorimotor cortex during surgery by cortical surface recording of somatosensory evoked potentials. J Neurosurg 68:99-111, 1988

48. Woolsey CN, Erickson TC, Gilson WE: Localization in somatic sensory and motor areas of human cerebral cortex as determined by direct recording of evoked potentials and electrical stimulation. J Neurosurg 51:476-506, 1979

49. Yetkin FZ, Papke RA, Mark LP, et al: Location of the sensorimotor cortex: functional and conventional MR compared. AJNR 16:2109-2113, 1995

50. Yousry TA, Schmid UD, Jassoy AG, et al: Topography of the cortical motor hand area: prospective study with functional MR imaging and direct motor mapping at surgery. Radiology 195:23-29, 1995

51. Yousry TA, Schmid UD, Schmidt D, et al: The central sulcal vein: a landmark for identification of the central sulcus using functional magnetic resonance imaging. J Neurosurg 85:608-617, 1996

Manuscript received December 8, 1998. 
Accepted in final form February 3, 1999.

This study was partly supported by the Swiss National Foundation Grants Nos. 31-42180.94 and 4038-052837/1 to Dr. Kollias, and Grant No. 812H-055191 to Dr. Fandino.

Address reprint requests to: Javier Fandino, M.D., Department of Neurosurgery, University Hospital of Zurich, Rämistrasse 100, 8091 Zurich, Switzerland. email: fandino@nch.unizh.ch. 